\title{
Low-Level Environmental Heavy Metals are Associated with Obesity Among Postmenopausal Women in a Southern State
}

\author{
Shelbie Stahr ${ }^{1}$ (D) Tung-chin Chiang ${ }^{2} \cdot$ Michael A. Bauer $^{3} \cdot$ Gail A. Runnells ${ }^{4} \cdot$ Lora J. Rogers $^{5} \cdot$ Huyen Vi Do $^{4}$. \\ Susan A. Kadlubar ${ }^{2} \cdot$ L. Joseph Su ${ }^{4}$
}

Received: 21 August 2020 / Revised: 23 November 2020 / Accepted: 15 December 2020 / Published online: 17 January 2021

(c) The Author(s) 2021

\begin{abstract}
Both arsenic and cadmium are reported to be toxic to humans. The use of saliva as a biomarker of low-level exposures to these elements has not been adequately explored, and the putative relationship between exposure and obesity is unclear. This cross-sectional study aims to investigate the relationship between salivary arsenic and cadmium concentrations and their association with obesity. Arsenic and cadmium concentrations were analyzed in human saliva samples by Inductively Coupled Plasma-Mass Spectrometry on 270 randomly selected women who participated in the Arkansas Rural Community Health Study. Multivariable logistic regression was performed to evaluate the association between heavy metal concentrations and obesity. Stratified logistic regression was performed based on menopausal status. Generalized linear models were used to evaluate weight gain velocity. Significant positive associations were observed in postmenopausal women for both arsenic $(\mathrm{OR}=4.43,95 \% \mathrm{CI} 1.91-10.28)$ and cadmium $(\mathrm{OR}=2.72,95 \% \mathrm{CI} 1.23-5.99)$ concentrations, as well as significant trends among tertiles ( $p<0.01$ and $p=0.01$, respectively). No relationship with obesity was evident among premenopausal women for either metal. A dose-response relationship was observed between increasing weight gain velocity and increasing metal concentrations. At concentrations well below governmental and industrial standards for acute toxicity, significant associations between obesity and concentration of these heavy metals are evident. The rate at which individuals gain weight is affected by metal concentrations and may play a role in the rapid increase in weight in postmenopausal women. These results might explain, in part, the missing variability in the increasing obesity pandemic in certain population exposed to these environmental toxicants.
\end{abstract}

Keywords Arsenic $\cdot$ Cadmium $\cdot$ Obesity $\cdot$ Saliva $\cdot$ Menopause

Shelbie Stahr

SStahr@uams.edu

Tung-chin Chiang

TChiang@uams.edu

Michael A. Bauer

MBAUER2@uams.edu

Gail A. Runnells

RunnellsGailAnn@uams.edu

Lora J. Rogers

LJRogers@uams.edu

Huyen Vi Do

dohuyenv@gmail.com

Susan A. Kadlubar

sakadlubar@gmail.com

L. Joseph Su

ljsu@uams.edu
1 Interdisciplinary Biomedical Sciences, Department of Clinical and Translational Sciences, University of Arkansas Medical Sciences, 4301 W. Markham St. Slot \#601, Little Rock, AR 72205, USA

2 Department of Environmental and Occupational Health, Fay W. Boozman College of Public Health, University of Arkansas Medical Sciences, 4301 West Markham, \# 820, Little Rock, AR 72205, USA

3 Department of Biomedical Informatics, College of Medicine, University of Arkansas Medical Sciences, 4018 W Capitol Ave, Little Rock, AR 72205, USA

4 Department of Epidemiology, Fay W. Boozman College of Public Health, University of Arkansas Medical Sciences, 4301 W. Markham St. \# 820, Little Rock, AR 72205, USA

5 COPH Department of Epidemiology Slot 721-21, Winthrop P. Rockefeller Cancer Institute, Fay W. Boozman College of Public Health, University of Arkansas for Medical Sciences, 4104 Outpatient Circle, Little Rock, AR 72205-7101, USA 


\section{Introduction}

Hundreds of millions of dollars are spent to prevent obesity in the United States annually (Lanza et al. 2010; Kruger et al. 2004); however, obesity rates over the past 50 years continue to climb (Wang et al. 2020). It is estimated that approximately $38 \%$ of US adults are defined as obese (NCHS 2016). Factors contributing to obesity include lack of physical activity and exercise, imbalance of energy intake and expenditure, a high sedentary lifestyle, intake of high-caloric foods, stress, genetics, and health/ medical conditions (Eunice Kennedy Shriver National Institute of Child Health and Human Development 2016; Lopomo et al. 2016). The National Institute of Health has concluded that the greatest contributor to weight gain is the imbalance between caloric intake and energy expenditure (Eunice Kennedy Shriver National Institute of Child Health and Human Development 2016), but recent studies demonstrate that these factors do not fully explain the obesity problem (Park et al. 2017; Lopomo et al. 2016).

As of 2019, arsenic ranks number one on the Agency for Toxic Substances and Disease Registries (ATSDR) list of hazardous substance Priority List (ATSDR 2020). This list is created by utilizing an algorithm that takes into account the toxicity, potential for human exposure, as well as the frequency of human exposure (ATSDR 2020). Exposure to high levels of arsenic can cause skin lesions, cardiovascular disease, neurological effects, diabetogenic effects, and various forms of cancer (ATSDR 2011a; IARC 2012a). The effect of arsenic exposure in low doses remains controversial in the literature (Schmidt 2014). General population exposures to arsenic are largely attributed to contaminated food, water, and air ingestion averaging between 20 and $300 \mu \mathrm{g} / \mathrm{day}$ (IARC 2012a). Arsenic (As) is a naturally occurring metalloid that is ubiquitous in the environment. Arkansas is among several states along the Mississippi Delta region, which reports the highest levels of arsenic in the U.S. (Smith et al. 2017). Individuals residing in the state experience chronic low-dose exposures to these metals, and the health effects are not yet clear.

While arsenic is known to have harmful health effects regardless of gender, there are some consequences that are unique to women. Numerous studies have shown that pregnant women, fetuses, and neonates all suffer adverse pregnancy outcomes when exposed to arsenic (Milton et al. 2005, 2017; Rahman et al. 2009; Farzan et al. 2013; Ronco et al. 2010). Particularly for exposed mothers, hypertensive disorders have been reported at higher rates than in the general population. Studies of pregnant women in Chile and Romania have identified associations between adverse health outcomes among mothers consumed drinking water with arsenic concentrations of $40 \mu \mathrm{g} / \mathrm{L}$ (Hopenhayn et al.
2006; Munoz et al. 2018; Surdu et al. 2015). Arsenic has also been identified as an endocrine disrupter in various in vivo, in utero, and cell culture models (Chatterjee and Chatterji 2010; Davey et al. 2007; Waalkes et al. 2004). These disruptions can cause adverse developmental, reproductive, neurological, and immune effects (Alvarado-Cruz et al. 2018; Ashrap et al. 2019; Chen et al. 2009; Iavicoli et al. 2009; Liu et al. 2015; White et al. 2019). One study reported that an increase in arsenic resulted in decreased levels of estradiol that presented in a dose-response manner within a rat model (Chatterjee and Chatterji 2010). The study further describes that arsenic may mimic the estrogen mechanisms that disrupt the endocrine signaling pathway and reproductive failures.

Lesser known consequences of arsenic exposure have been observed in both experimental and epidemiological studies regarding the relationship between arsenic and obesity. An in vitro study published in 2011 concluded that prolonged inorganic arsenite exposure resulted in decreased expression in glucose transporter type 4 (GLUT4) and several adipogenic genes (Xue et al. 2011). This study indicates that prolonged exposure to arsenic causes significant effects on adipocytes (Xue et al. 2011). Similarly, an in utero study published in 2016 found that mice with early life exposure to arsenite resulted in abnormal metabolism, increased body weight, as well as other cardiometabolic risk factors (Ditzel et al. 2016). Unlike these experimental studies, epidemiological studies are less consistent. High BMI was associated with a low percentage of urinary arsenic excreted as monomethylarsonic acid in women (Gomez-Rubio et al. 2011). Contrarily, in 2010 a study evaluating if arsenic was associated with body composition in reproductive-age women found that there was no association between the two after adjusting for food consumption and lifestyle factors (Ronco et al. 2010).

Cadmium (Cd) has long been recognized as an environmental risk factor for multi-organ dysfunction and has been determined to play a role in the pathogenesis of obesity, diabetes, and the metabolic syndrome (Tinkov et al. 2017). Like arsenic, cadmium is ubiquitous in the environment and is in the top ten environmental chemicals of concern to environmental health agencies (Park et al. 2017). There is an abundance of literature focusing on cadmium exposure via in utero, perinatal, and infant exposure, but limited data on the relationship between adult exposure and obesity exist (Park et al. 2017). Human studies have produced conflicting results (Tinkov et al. 2017). Data from the National Health \& Nutrition Examination Survey (NHANES), reported urine cadmium concentrations were negatively associated with BMI, waist circumference, and obesity (Padilla et al. 2010). However, a study utilizing blood cadmium levels reported a positive association between cadmium and BMI, as well as cadmium and dyslipidemia (Zhou et al. 2016). 
The obesity epidemic has dramatically increased, particularly in the southern region of the United States (CDC 2019), including Arkansas. Among women, Arkansas has the highest prevalence of obesity compared to all other states (America's Health Rankings 2020). This study conducted in an Arkansas population aimed to identify other putative contributors to the growing obesity epidemic. We sought to evaluate the potential association of arsenic and cadmium with obesity among women in Arkansas, where obesity and exposure to these elements are prevalent.

\section{Methods}

\section{Study Population}

Data obtained from the Arkansas Rural Community Health (ARCH) Study cohort, formerly known as Spit for the Cure (Bondurant et al. 2011; Lee et al. 2014; McElfish et al. 2019) was utilized in the present study. All 75 counties in Arkansas are represented in this cohort, including an overrepresentation of African Americans. The ARCH population was not intended to be representative of the entire female population of Arkansas. In addition to being a racially diverse cohort, it is also comprised of individuals with a higher education attainment compared to the overall state average. Data were collected at baseline that contained information regarding, family and medical history, specific information regarding breast cancer history and treatment, reproductive health, physical activity, and socioeconomic status. For each participant, a baseline $2 \mathrm{~mL}$ self-collection saliva sample was collected at the time of study enrollment. Baseline information was collected through various community events from a total of 26,347 women between the ages of 18 and 100.

A random sample of 270 subjects $(\sim 1 \%$ of the ARCH cohort) was selected and concentrations for arsenic and cadmium were quantified for the present study. This study is pilot in nature to explore our hypothesis. Future studies utilizing a larger sample size from the cohort with prospective follow-up will be conducted as well as the addition of more underlying conditions. Baseline questionnaire data were used for analysis, as well as $400 \mu \mathrm{L}$ of the baseline saliva sample.

\section{Sample Preparation and Quantification by ICP-MS}

Participants were asked to refrain from eating or drinking at least 30 min prior to providing a saliva sample. Participants were also discouraged from providing a sputum sample, as mucus was not desired. Roughly $200 \mu \mathrm{L}$ of a spit sample was mixed with equal parts Oragene DNA (OG-250) stabilizing solution (DNA Genotek, Ottawa, Ontario, Canada) (Barai et al. 2017), inverted 3-4 times to ensure distribution of solution and stored in the dark at room temperature until analysis. To obtain arsenic and cadmium concentrations, samples were analyzed using a Thermo Fisher Scientific iCAP RQ ICP-MS (Thermo Fisher Scientific, Waltham, MA).

Multi-element ICP-MS stock standard and internal standards of $10 \mu \mathrm{g} / \mathrm{mL}$ was purchased from Inorganic Ventures, Christiansburg, VA. A second source quality control standard $(100 \mu \mathrm{g} / \mathrm{mL})$ was purchased from SPEX CertiPrep, Metuchen, NJ. Nitric acid trace metal grade and ethyl alcohol was purchased from Fisher Chemical, Fair Lawn, NJ. The sample diluent used to prepare the standards, quality controls, and samples consisted of $2 \%(\mathrm{v} / \mathrm{v})$ nitric acid and ethanol.

Arsenic and cadmium, among other elements, are in the multi-element ICP-MS stock standard and quality control standard solutions. The internal standard used for ICP-MS analysis was Yttrium $(10 \mu \mathrm{g} / \mathrm{L})$. Saliva samples were homogenized by inverting several times prior to analysis. All samples were analyzed in kinetic energy discrimination (KED) mode. Blank Oragene DNA stabilizing solution without saliva was tested and confirmed no measurable trace element of interest.

To verify that all samples utilized produced valid numbers, samples were compared against the Background Equivalent Concentration (BEC) (Wilschefski and Baxter 2019; Thomas 2004; CASRN E. S. C. E. S. 2014). The BEC is used to assure that the signals used in sample quantification are not due to "signal noise" resulting from background interference (CASRN E. S. C. E. S. 2014). The literature states that utilization of the BEC is a more reliable assessment in real-world sample matrices in regards to instrument performance (Thomas 2004), due to the quantification of the background level. In the present study, three arsenic concentrations were below its respective BEC value, and one cadmium fell below its respective BEC. For purposes of analyses, these values were recorded as " 0.00 " due to the variable being analyzed in tertiles. When reporting the measures of central tendency, these values were excluded from the analysis. Less than $1.0 \%$ of cadmium concentrations were recorded below BEC and $1.1 \%$ of arsenic concentrations fell below their respective BEC values.

\section{Obesity}

At baseline, participants self-reported their height (in.) and weight (lb.), to which the participants' body mass index (BMI) was calculated with the following formula: $\mathrm{BMI}=\left[\right.$ weight $(\mathrm{kg}) /$ height $\left.\left(\mathrm{m}^{2}\right)\right]$. If a participant had a BMI of greater than or equal to 30 , they were defined as obese. If the BMI was between 18.5 and less than 30 , they were defined as non-obese. Individuals with unreliable data, 
such as outliers or data entry errors, were removed from the analysis $(n=4)$.

The weight gain velocity (WGV) was calculated with the formula below to observe potential associations in the rate of weight gain with different concentrations of arsenic and cadmium. Individuals were asked to self-report their best approximation of their weight at age 18 during the baseline survey. If there were missing records for an individual's weight, age, or weight at age 18 , their WGV was reported as missing $(n=1)$ :

Weight Gain Velocity $=\frac{(\text { Weight at enrollment }- \text { Weight at age } 18)}{(\text { Age at enrollment }-8)}$

\section{Other Covariates}

Sociodemographic information provided in the baseline survey such as race, hormone use, region of residence, education, breastfeeding/parity, alcohol use, age, physical activity, and age at last menstrual cycle were included to identify confounding effects and effect modification. The variables race, hormone use, region, education, breastfeeding/ parity, and alcohol use were analyzed as categorical variables, while the variables age, physical activity, and age at last menstrual cycle were analyzed as continuous variables. Physical activity was a composite variable that varied from walking to vigorous activity, resulting in total hours per week. Race was analyzed as a categorical variable, white/ European American (EA), black/African American (AA), and other. In the final stratified models, other racial groups were excluded from the analysis due to insufficient sample size $(n=12)$ and race was analyzed as a dichotomous variable, EA and AA. Hormone use was analyzed as a dichotomous variable (yes/no), relating to the participants' menstrual cycle. Region was analyzed as a dichotomous variable as either Rural or Urban, classified by the subjects' zip code at baseline using the rural-urban commuting area (RUCA) codes. Participants' parity and breastfeeding practices were combined to create a composite variable with the following three possible outcomes: Nulliparous and never breastfed, given birth to at least one child and never breastfed, or given birth to at least one child and breastfed. This composite was created to avoid multicollinearity being introduced into the statistical models.

\section{Exclusions}

Participants were excluded from the study to eliminate potential bias. Individuals that recorded non-reliable or missing value for height or weight, or a record of a $\mathrm{BMI}<18.5$ or $>60$ were excluded from the analysis $(n=11)$. When analyzing the adjusted models, individuals were excluded in the analysis if a covariate utilized in the specific model was recorded as missing $(n=14)$. As previously described, data obtained for the current study were obtained from the existing ARCH study cohort. The ARCH cohort was established to study the risk and effects of breast cancer. In the current study, breast cancer cases were excluded $(n=8)$, to omit any potential bias that were associated with any treatment, lifestyle, or genetic factors.

\section{Statistical Analyses}

Differences in patient characteristics between non-obese and obese individuals were evaluated using $\mathrm{X}^{2}$ test for categorical variables and $\mathrm{t}$-tests for continuous variables. Both arsenic and cadmium concentrations were categorized into three levels based on the overall cohort distribution; the first level belonging to individuals with the lowest third of the specific element concentration, the second level comprised of the middle $33 \%$ of the concentrations, and the highest tertile contains the highest third of the specific element concentrations. Distributions of both arsenic and cadmium were determined by evaluating the measures of central tendency.

Linear regression models were attempted to observe the relationship between arsenic and cadmium and their association to obesity, while using BMI as the continuous outcome. Due to majority of participants had very low concentrations of these heavy metals, the data were heavily skewed such that normalization could not be achieved (data not shown). However, after producing stratified models, a $\log _{10}$ normalization was attempted and successful for postmenopausal women and two regression models examining arsenic and cadmium as continuous exposures with the outcome of obesity was performed producing odds ratios (ORs) and $95 \%$ confidence intervals $(95 \% \mathrm{CI})$. Heavy metal data of premenopausal women were unable to be adequately normalized, and therefore linear regression was not possible at the time, this is likely due to the small sample size.

Unconditional logistic regression was used to estimate unadjusted and multivariable-adjusted ORs and 95\% CIs to estimate associations between increased likelihood for obesity and each metal concentration category. Tests for trend were performed by assessing median of arsenic and cadmium concentration tertiles as ordinal variables in the logistic regression model to observe their associations with obesity. These models were created due to the low concentrations of both arsenic and cadmium, to better observe a difference between relative "low", "medium", and "high" values.

Potential confounding variables for the association between obesity and arsenic and cadmium concentrations were included in the multivariable logistic regression models. Confounding variables were selected based on a priori knowledge, as well as a $10 \%$ change in the beta coefficient. 
The most parsimonious model was used for each analysis to estimate associations with obesity and arsenic and cadmium concentrations. The following covariates were used in at least one of the models presented: age, ethnicity, menopausal status, parity/breastfeeding history, age at last menstrual cycle, and alcohol use. Stratified models were used to analyze obesity with arsenic and cadmium concentrations for both premenopausal and postmenopausal women, using two different models. Generalized linear models were used to examine the regression between WGV and various metal quartiles, and comparisons were made using the lowest quartile as a reference. WGV was analyzed utilizing arsenic and cadmium quartiles rather than tertiles due to the larger sample size allowing for further categorizations to better investigate the relationship.

Interaction was assessed between arsenic and cadmium using a multiplicative model utilizing $75 \%$ cutoff points to determine the effects of "high" and "low" concentrations of each heavy metal. The test for interaction did not produce significant results; however, high arsenic values appear to enhance the associations. Therefore, we produced separate final models for arsenic and cadmium.

Each analysis performed was two-sided with $\mathrm{p}$ values of $\alpha$ less than 0.05. All analyses were performed using SAS version 9.3.

\section{Results}

Demographic information stratified by both obesity and menopausal status is shown in Table 1 . The cohort overall was split evenly between non-obese and obese women ( $51.9 \%$ vs. $48.1 \%$, respectively). The study population consists of 78 women who identified as being premenopausal and 192 postmenopausal women. Among non-obese premenopausal women, the majority self-identified as European American (EA) (77.8\%), whereas the majority of the obese premenopausal women self-identified as African American (AA) (59.5\%). In the postmenopausal group, a large percentage of both non-obese and obese individuals identified as EA $(69.2 \%$ and $60.2 \%$, respectively). Regardless of obesity status, the majority of study participants live in rural regions of Arkansas. No premenopausal women reported using hormone therapy. Among postmenopausal women, similar percentages reported using hormones for both non-obese and obese individuals ( $11.5 \%$ and $11.4 \%$, respectively). Premenopausal women differed in education status when separated by obesity. The majority of non-obese individuals attended some college or technical school, whereas obese individuals primarily completed a high school degree or GED. The majority of postmenopausal women, regardless of obesity status, completed a high school degree or GED as their highest form of education obtained. The distribution of age since menopause among postmenopausal women is rather uniform, regardless of obesity status, with roughly $30 \%$ in each category. When the variable of parity and breastfeeding were combined into one composite variable, premenopausal non-obese women mainly gave birth to children and did breastfeed (52.8\%) compared to the other categories, whereas premenopausal obese women, as well as all postmenopausal women primarily gave birth to children and did not participate in breastfeeding $(50.0 \%, 54.8 \%$, and $48.9 \%$ respectively). The majority of women in the study, both non-obese and obese, premenopausal and postmenopausal women reported their alcohol consumption as never to once a year.

The distribution of BMI was similar among premenopausal and postmenopausal women. Among premenopausal women, the non-obese women had a mean BMI of $24 \mathrm{~kg} /$ $\mathrm{m}^{2}$, whereas obese women had a mean BMI of $38 \mathrm{~kg} / \mathrm{m}^{2}$. Similarly, postmenopausal non-obese women had a BMI of $27 \mathrm{~kg} / \mathrm{m}^{2}$, and obese women recorded a higher BMI of $37 \mathrm{~kg} /$ $\mathrm{m}^{2}$. Premenopausal women displayed an almost 23-lb difference between non-obese and obese self-reported weight at age 18, whereas postmenopausal women reported a smaller gap of $7.4 \mathrm{lb}$. Regardless of the menopausal group, the nonobese women reported lower weights at age 18 compared to obese women. The mean ages for each group of women ranged from 44 years of age to 59 years of age. Premenopausal women recorded more hours per week participating in physical activity compared to postmenopausal women. The age at which women underwent menarche was consistent across all groups.

Distributions of both arsenic and cadmium are detailed in Table 2. All concentrations, regardless of element, are below the safety limits set by the Centers for Disease Control and Prevention (CDC), World Health Organization (WHO), Food and Drug Administration (FDA), and the Agency for Toxic Substances and Disease Registry (ATSDR) (ATSDR $2011 \mathrm{a}, \mathrm{b}$ ). The mean arsenic values for both premenopausal and postmenopausal women are higher for obese women compared to non-obese women $(0.028 \mu \mathrm{g} / \mathrm{L}, 0.023 \mu \mathrm{g} / \mathrm{L}$ vs. $0.022 \mu \mathrm{g} / \mathrm{L}, 0.020 \mu \mathrm{g} / \mathrm{L}$, respectively). When cadmium concentrations were considered, mean distributions differed by menopausal status. Premenopausal women had higher mean cadmium concentrations among non-obese women compared to obese $(0.026 \mu \mathrm{g} / \mathrm{L}$ and $0.019 \mu \mathrm{g} / \mathrm{L}$, respectively). Among postmenopausal women, those that were obese had a higher mean cadmium concentration compared to those who identified as non-obese $(0.110 \mu \mathrm{g} / \mathrm{L}$ and $0.020 \mu \mathrm{g} / \mathrm{L}$, respectively). It should be noted that one individual in the study population had a significantly higher cadmium concentration that the rest of the participants; however, when excluding this participant, the relationships between obese and non-obese individuals remain (results not shown). 
Table 1 Sociodemographic characteristics of the population by obese status and menopausal status

\begin{tabular}{|c|c|c|c|c|c|c|c|c|}
\hline \multirow[t]{3}{*}{ Characteristic } & \multicolumn{4}{|c|}{ Premenopausal women } & \multicolumn{4}{|c|}{ Postmenopausal women } \\
\hline & \multicolumn{2}{|c|}{ Non-obese $\dagger$} & \multicolumn{2}{|l|}{ Obese $\dagger$} & \multicolumn{2}{|c|}{ Non-obese $\dagger$} & \multicolumn{2}{|l|}{ Obese $\dagger$} \\
\hline & $N=36$ & $(\%)$ & $N=42$ & $(\%)$ & $N=104$ & $(\%)$ & $N=88$ & $(\%)$ \\
\hline \multicolumn{9}{|l|}{ Race } \\
\hline AA/African American & 6 & $(16.7)$ & 25 & $(59.5)$ & 26 & $(25.0)$ & 33 & $(37.5)$ \\
\hline EA/European American & 28 & $(77.8)$ & 17 & $(40.5)$ & 72 & $(69.2)$ & 53 & $(60.2)$ \\
\hline Missing & 2 & $(5.5)$ & 0 & $(0.0)$ & 6 & $(5.8)$ & 2 & $(2.3)$ \\
\hline \multicolumn{9}{|l|}{ Region } \\
\hline Rural & 36 & $(100.0)$ & 37 & $(88.1)$ & 99 & $(95.2)$ & 84 & $(95.5)$ \\
\hline Urban & 0 & $(0.0)$ & 5 & $(11.9)$ & 4 & $(3.8)$ & 3 & $(3.4)$ \\
\hline Missing & 0 & $(0.0)$ & 0 & $(0.0)$ & 1 & $(1.0)$ & 1 & $(1.1)$ \\
\hline \multicolumn{9}{|l|}{ Hormone use } \\
\hline Yes & 0 & $(0.0)$ & 0 & $(0.0)$ & 12 & $(11.5)$ & 10 & (11.4) \\
\hline No & 36 & $(100.0)$ & 42 & $(100.0)$ & 92 & $(88.5)$ & 78 & $(88.6)$ \\
\hline Missing & 0 & $(0.0)$ & 0 & $(0.0)$ & 0 & $(0.0)$ & 0 & $(0.0)$ \\
\hline \multicolumn{9}{|l|}{ Education } \\
\hline Less than high school & 2 & $(5.6)$ & 3 & $(7.1)$ & 16 & $(15.4)$ & 14 & $(15.9)$ \\
\hline High school graduate or GED & 11 & $(30.5)$ & 16 & $(38.1)$ & 42 & $(40.4)$ & 35 & $(39.8)$ \\
\hline Some college or technical school & 14 & $(38.9)$ & 15 & $(35.7)$ & 26 & $(25.0)$ & 30 & $(34.1)$ \\
\hline College or post graduate & 9 & $(25.0)$ & 8 & $(19.1)$ & 20 & $(19.2)$ & 9 & $(10.2)$ \\
\hline Missing & 0 & $(0.0)$ & 0 & $(0.0)$ & 0 & $(0.0)$ & 0 & $(0.0)$ \\
\hline \multicolumn{9}{|l|}{ Menopausal status } \\
\hline Premenopausal & 36 & $(100.0)$ & 42 & $(100.0)$ & 0 & $(0.0)$ & 0 & $(0.0)$ \\
\hline Postmenopausal for $\leq 10$ years & 0 & $(0.0)$ & 0 & $(0.0)$ & 34 & $(32.7)$ & 29 & $(33.0)$ \\
\hline Postmenopausal for 10-21 years & 0 & $(0.0)$ & 0 & $(0.0)$ & 33 & $(31.7)$ & 34 & $(38.6)$ \\
\hline Postmenopausal for $>21$ years & 0 & $(0.0)$ & 0 & $(0.0)$ & 37 & $(35.6)$ & 25 & $(28.4)$ \\
\hline Missing & 0 & $(0.0)$ & 0 & $(0.0)$ & 0 & $(0.0)$ & 0 & $(0.0)$ \\
\hline \multicolumn{9}{|l|}{ Children and breastfeeding } \\
\hline Not given birth and not breastfeed & 2 & $(5.5)$ & 5 & $(11.9)$ & 8 & $(7.7)$ & 12 & $(13.6)$ \\
\hline Given birth and not breastfed & 15 & $(41.7)$ & 21 & $(50.0)$ & 57 & $(54.8)$ & 43 & $(48.9)$ \\
\hline Given birth and breastfed & 19 & $(52.8)$ & 16 & $(38.1)$ & 38 & $(36.5)$ & 30 & $(34.1)$ \\
\hline Missing & 0 & $(0.0)$ & 0 & $(0.0)$ & 1 & $(1.0)$ & 3 & $(3.4)$ \\
\hline \multicolumn{9}{|l|}{ Alcohol use } \\
\hline Never to once a year & 26 & $(72.2)$ & 26 & $(61.9)$ & 78 & $(75.0)$ & 77 & $(87.5)$ \\
\hline Once a month & 5 & $(13.9)$ & 11 & $(26.2)$ & 10 & $(9.6)$ & 3 & $(3.4)$ \\
\hline Once a week to several times a week & 4 & $(11.1)$ & 4 & $(9.5)$ & 14 & $(13.5)$ & 5 & $(5.7)$ \\
\hline Every day & 1 & $(2.8)$ & 1 & $(2.4)$ & 2 & $(1.9)$ & 2 & $(2.3)$ \\
\hline \multirow[t]{2}{*}{ Missing } & 0 & $(0.0)$ & 0 & $(0.0)$ & 0 & $(0.0)$ & 1 & $(1.1)$ \\
\hline & Mean $\neq$ & $(\mathrm{SD})$ & Mean $\neq$ & $(\mathrm{SD})$ & Mean $\ddagger$ & $(\mathrm{SD})$ & Mean $\neq$ & $(\mathrm{SD})$ \\
\hline BMI & 24 & $(3.0)$ & 38 & $(6.0)$ & 27 & $(2.7)$ & 37 & $(4.8)$ \\
\hline Missing & 0 & & 0 & & 0 & & 0 & \\
\hline Weight at 18 years of age (lbs.) & 117.4 & $(16.5)$ & 140.3 & $(38.8)$ & 122.2 & $(26.1)$ & 129.6 & $(29.3)$ \\
\hline Missing & 0 & & 0 & & 2 & & 0 & \\
\hline Baseline Age (yrs.) & 44 & $(6.7)$ & 46 & $(5.2)$ & 59 & $(8.8)$ & 58 & $(8.1)$ \\
\hline Missing & 0 & & 0 & & 0 & & 0 & \\
\hline Physical Activity (hrs. per week) & 17.5 & $(1207.3)$ & 20.5 & $(1590.7)$ & 15.3 & $(1290.6)$ & 12.1 & $(874.3)$ \\
\hline Missing & 0 & & 0 & & 0 & & 0 & \\
\hline Age at first menstrual cycle & 13 & $(2.0)$ & 13 & $(2.0)$ & 13 & $(1.8)$ & 12 & $(1.8)$ \\
\hline Missing & 0 & & 1 & & 0 & & 0 & \\
\hline
\end{tabular}

$S D$ standard deviation, BMI Body mass index, lbs. Pounds, hrs. Hours, yrs. Years

${ }^{\dagger}$ Chi-square test for categorical variables

†-test for continuous variables

$\mathrm{p}$ values calculated excluding the missing values 
Table 2 Descriptive statistics by element concentration, obese status, and menopausal status

\begin{tabular}{|c|c|c|c|c|c|c|c|c|c|c|c|c|}
\hline \multirow[t]{2}{*}{ Arsenic } & \multicolumn{6}{|c|}{ Premenopausal women } & \multicolumn{6}{|c|}{ Postmenopausal women } \\
\hline & $\mathrm{N}$ & Mean & Median & SD & Min & $\operatorname{Max}$ & $\mathrm{N}$ & Mean & Median & SD & Min & $\operatorname{Max}$ \\
\hline Obese & 41 & 0.028 & 0.017 & 0.044 & 0.008 & 0.261 & 88 & 0.023 & 0.022 & 0.012 & 0.008 & 0.086 \\
\hline Non-obese & 35 & 0.022 & 0.019 & 0.011 & 0.007 & 0.048 & 103 & 0.020 & 0.017 & 0.012 & 0.007 & 0.090 \\
\hline \multicolumn{13}{|l|}{ Cadmium } \\
\hline Obese & 42 & 0.019 & 0.016 & 0.019 & 0.003 & 0.092 & 88 & 0.110 & 0.012 & 0.655 & 0.002 & 6.144 \\
\hline Non-obese & 36 & 0.026 & 0.017 & 0.030 & 0.002 & 0.169 & 104 & 0.020 & 0.011 & 0.029 & 0.001 & 0.209 \\
\hline
\end{tabular}

*Excluding concentrations that were below BEC

**Mean, Median, Min. and Max. are shown in $\mu \mathrm{g} / \mathrm{L}$

Table 3 displays the associations between obesity and metal concentrations. No models comprised of premenopausal women produced significant relationships or trends regarding metal concentration and obesity. Among postmenopausal women, relationships between obese and heavy metals were evident. A significant association was observed for increasing concentrations of arsenic and risk for obesity, including a significant trend $(P$ for trend $<0.01)$. Although the relationship with obesity was less robust, cadmium concentrations followed a similar direction. A significant increase in risk for obesity can be seen with increasing cadmium concentrations, as well as a significant trend ( $\mathrm{P}$ for trend $=0.01)$. These trends suggest a dose-response for both arsenic and cadmium, and their relationship with an increased risk for obesity. Observing arsenic as a continuous variable for postmenopausal women was also produced and yielded statistically significant results similar to results of the logistic regression models. For every 10 unit increase in arsenic, the odds of being obese increase by a factor of 19.01. Similarly, for every 10 unit increase in cadmium, the odds of being obese increase by a factor of 2.64 . Models were only ran among postmenopausal women, as premenopausal women did not fit a normal distribution among heavy metals. Weight gain velocity was calculated to identify potential associations between metal concentrations and the rate of weight gain since 18 years of age. Figure 1 displays the comparison of mean metal concentrations displayed in quartiles compared to their respective weight gain velocities. While only the first and fourth arsenic quartile show a statistically significant difference $(p<0.05)$, the overall positive trend can be seen for increasing metal concentration and increasing weight gain velocity for both cadmium and arsenic that suggest dose-response relationships.

\section{Discussion}

Associations between both salivary arsenic and cadmium concentrations and obesity were examined in a pilot study using data from a cohort of Arkansan women. The associations found in this study relating to obesity were evident only among postmenopausal women. While it is known that weight gain is a common result after menopause (AlSafi and Polotsky 2015; Lovejoy 2003), a change in fat distribution also occurs (Lovejoy 2003; Al-Safi and Polotsky 2015). While the mechanism is unclear, there are several factors that influence this distribution, such as hormone replacement therapy, age, and body composition (Lovejoy 2003). Another factor that should be recognized are estrogen levels. While there is sparse epidemiologic data regarding the relationship between estrogen and arsenic, the results produced from the current study support the existing evidence. The relationship seen between arsenic and obesity among postmenopausal women in the current study supports the relationship of a decrease in estrogens as a result of increased arsenic concentrations seen in other publications (Chatterjee and Chatterji 2010).

While these results are promising, the mechanisms of these relationships have yet to be ascertained.

Furthermore, there are several biologically plausible hypotheses of the associations between arsenic and obesity seen in this study.

Arsenic is typically measured in urine, blood, hair, and fingernails/toenails as appropriate biospecimens for exposure, while saliva is not as commonly used. Cadmium is more commonly measured in blood, urine, and kidney samples. A study published in West Bengal, India, analyzed saliva and concluded that salivary arsenic could be used as a potential biomarker of arsenic exposure, compared to urine arsenic concentrations $(r=0.60)$ (Bhowmick et al. 2013). A similar study published in Environmental Health and Preventative Medicine concluded that saliva might be utilized as a biological monitoring tool for arsenic, due to their correlation analysis finding significant positive correlations between total arsenic in urine and saliva $(r=0.794, p<0.01)$ (Wang et al. 2017). We also found a significantly correlation in our pilot study of 100 volunteers for the concentration of arsenic between saliva and urine $(r=0.60, p<0.01)$ after adjusting for age, race, sex, BMI, and smoking status 

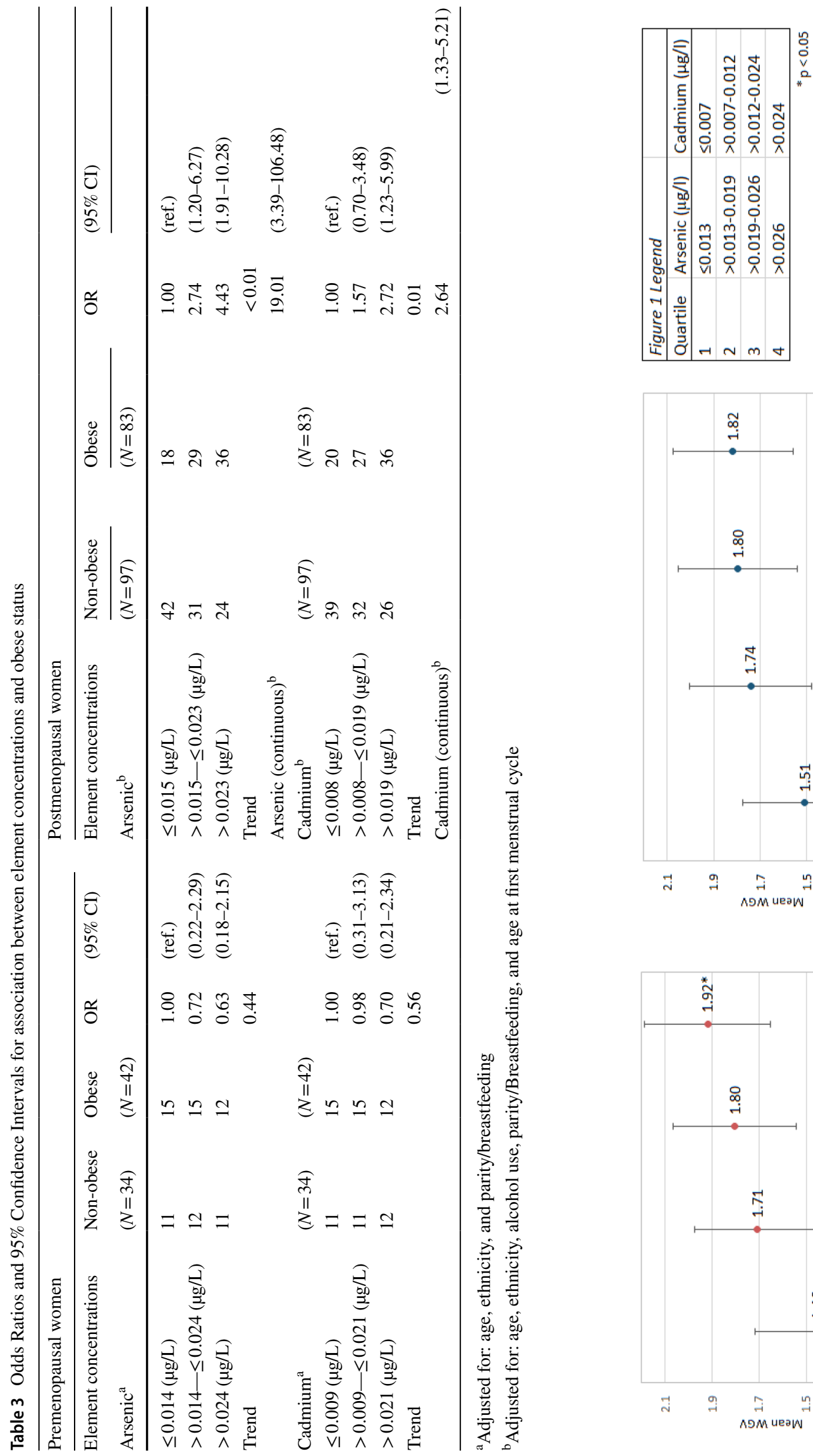

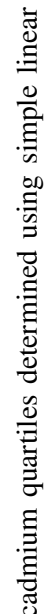

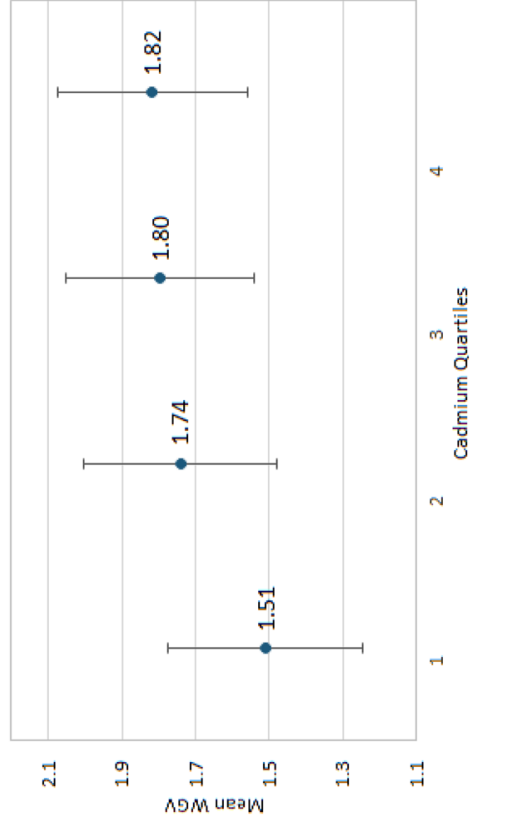

ฐี

寻

홍

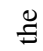

ญ్

푸

总

若 
(not published). Positive aspects of utilizing saliva as a biospecimen are that it is a relatively stable matrix compared to blood and urine, the processing and storage of the sample is less tedious compared to other biofluids, as well as the noninvasive procurement (Bhowmick et al. 2013; Wang et al. 2017). Limitations of the use of saliva are related to the fact that the matrix has a different chemical composition compared to blood or urine, the concentrations are considerably lower in saliva compared to traditional biological samples used (often 1 to 2 orders of magnitude lower than blood), and a lack of Standard Reference Material set by the US National Institute of Standards and Technology (Bhowmick et al. 2013; Wang et al. 2017).

The relationship between urinary arsenic concentration and BMI remains inconsistent in the exiting published reports. A study published in Toxicology and Applied Pharmacology in 2011 found that a decrease in urinary arsenic concentration is associated with an increase in BMI (GomezRubio et al. 2011). One hypothesized explanation for this relationship is that arsenic is stored and accumulates in adipose tissue. In the current study, postmenopausal women had a significant correlation with increasing arsenic concentrations and obesity. Fat distribution in women changes with menopausal status, where central/abdominal obesity is more prevalent among postmenopausal women, as are various hormone stores within this white adipose tissue (Garaulet et al. 2002; Ferrara et al. 2002; Hodson et al. 2015; Lovejoy, 2003; Ceja-Galicia et al. 2017). The decreased urinary arsenic concentration associated with an increase in BMI could possibly be explained by the urinary quantification. With the arsenic being stored in adipose tissues and only a marginal amount being excreted in the urine, it is possible that a low amount of arsenic is associated with a high BMI. In reality, these results are due to a large concentration of arsenic present, but it is stored in the adipose tissue, thus causing a bias moving away from the null value, and could explain a number of study findings in the literature.

In contrast, fewer results published have concluded that an increase in urinary arsenic concentration is associated with a decrease in BMI (Ronco et al. 2010); however, the inverse relationship can still be explained by the same mechanism as described above. With a low BMI, there is not an abundance of adipose tissue to be utilized for arsenic storage, and therefore the majority is excreted in the urine. These results can inaccurately depict that high urinary arsenic is associated with a low BMI, where, in reality, there is no arsenic being stored in the body and is all excreted, thus biasing the results.

By utilizing saliva, these potential biases can be avoided, as saliva does not undergo the same biological processes as urine. A paper published in Environmental Health Perspectives in 2017 suggested that the relationship between arsenic and obesity measured in urine can have drastically different results, depending upon the urine dilution adjustment method used (Bulka et al. 2017). In the present study, we report a more accurate representation of the arsenic-BMI relationship by the use of saliva as a biospecimen with less variation due to physiological factors.

Figure 1 depicts the results from the regression analysis of weight gain velocity. The study identified a positive association between the rate of weight gain since 18 years of age and elevated concentrations of salivary arsenic and cadmium. As shown in Table 3, a clear relationship between these metals and obesity is evident. Further analysis of this relative weight gain suggests that low amounts of metal concentrations affect the rate at which weight gain occurs in the lifespan. While the current study reports concentrations of As and $\mathrm{Cd}$ well below the governmental guidelines, a more diverse sample size with a larger range of concentrations could identify a more robust relationship between WGV and metal concentration. It is known that rapid weight gain causes nutritional deficiencies, excess adipose tissue accumulation, and increased pressure on various organ systems. With the concentrations of metals in the current study all below $1 \mathrm{ppb}$, these low concentrations could contribute to meaningful differences in $\mathrm{WGV}$, thus further investigations into these relationships are needed.

It should also be noted that the literature identifies that arsenic concentrations in saliva are considerably lower when compared to blood and urine (Wang et al. 2017; Bhowmick et al. 2013; Yuan et al. 2008), which was a major technical issue a few decades ago because the lower detection limit of Atomic Absorption Spectroscopy or earlier version of ICPMS was at part per million (ppm) or part per billion (ppb) level. The newer version of ICP-MS, as used in this study, is capable of detecting concentrations as low as parts per trillion (ppt). This allows us to reach extremely low detection limits within our population who were exposed to trace amounts of arsenic and cadmium that previous generation of instruments could not achieve. While arsenic and cadmium produce concentrations lower in saliva compared to blood and urine, their exposures remain the same, and with this study, we wish to identify the potential use of saliva as a biomarker for various metal exposures. Additionally, another primary advantage of this study is the ability to quantify both arsenic and cadmium concentrations simultaneously, allowing the concurrent observation of multiple elements and their relationship with obesity, with independent analyses per each element of interest.

This study has several limitations. First, there are covariates that were not recorded at baseline, such as smoking status and occupation, which would preferably be included in the analyses. Smoking and the effects on heavy metal concentrations are controversial in the literature (Garhammer et al. 2004). A separate pilot study consisting of 100 individuals did not provide any significant association between 
arsenic and cadmium concentration with smoking status (results not shown). Different occupational exposures can be related to elevated levels of arsenic and cadmium (IARC 2012a; b), as well as the risk for obesity (Church et al. 2011). Smoking is also an established cause of increased arsenic and cadmium concentrations in the body (Pappas 2011) and is associated with various occupational exposures (Sterling and Weinkam 1990). Another concern at baseline, several essential variables, such as height, weight, and weight at age 18 were collected as self-report data. These data were collected at the same interview as the saliva sample, which is a limitation of cross-sectional studies. We are unable to confirm the temporal relationship between the arsenic and cadmium concentrations with obesity. Another restriction is that the number of subjects included in subset analyses, particularly among premenopausal subjects, was relatively low. In the current study, the significant findings were among the postmenopausal women, while the premenopausal category failed to establish any significant correlations. With the sample size of 77 participants, we are unable to produce precise results, compared to that of the postmenopausal results where the sample sizes are more than doubled. However, a study published in Biological Trace Element Research produced similar results. Women aged 18-35 of childbearingage were analyzed for relationships between urinary arsenic concentrations and BMI as well as the fat mass percentage (Ronco et al. 2010). The results concluded that no significant relationships could be obtained. Therefore, while the current study has a smaller sample size for the stratification of premenopausal women, the results are consistent with the current literature.

In conclusion, the relationship between arsenic and obesity, as well as cadmium and obesity were observed in postmenopausal women, both with an evident dose-response relationship. The relationship is not evident among premenopausal women for either element. Measurement in saliva, rather than in blood or urine, produced meaningful results. While these concentrations are below the regulatory and governmental limits, they still show a significant association with obesity. The data presented in this study regarding low levels of arsenic and cadmium can inform governmental limits and guidelines regarding appropriate levels of human exposure. Information presented in the current study has revealed other possible explanations to the growing obesity epidemic. Additional research is needed to further examine the magnitude of effect arsenic and cadmium have on obesity. This study has demonstrated that saliva can be an appropriate biospecimen for various elements and should be further investigated. Future research including smoking habits to more specifically analyze metal concentrations as well as any potential confounders is necessary; ambient air pollution measurements to assess the sources of exposure to these metals is also needed.
Acknowledgments This study is indebted to volunteers and participants contributed to the ARCH.

Funding This research was supported by a grant from the Arkansas Breast Cancer Research Program and the University of Arkansas for Medical Sciences.

\section{Compliance with Ethical Standards}

Conflict of interest The authors declare that they have no conflict of interest.

Consent to Participate Informed consent was obtained from all individual participants included in the study.

Consent for Publication The authors affirm that human research participants provided informed consent for publication of the aggregate data produced in the study.

Open Access This article is licensed under a Creative Commons Attribution 4.0 International License, which permits use, sharing, adaptation, distribution and reproduction in any medium or format, as long as you give appropriate credit to the original author(s) and the source, provide a link to the Creative Commons licence, and indicate if changes were made. The images or other third party material in this article are included in the article's Creative Commons licence, unless indicated otherwise in a credit line to the material. If material is not included in the article's Creative Commons licence and your intended use is not permitted by statutory regulation or exceeds the permitted use, you will need to obtain permission directly from the copyright holder. To view a copy of this licence, visit http://creativecommons.org/licenses/by/4.0/.

\section{References}

Al-Safi ZA, Polotsky AJ (2015) Obesity and menopause. Best Pract Res ClinObstetGynaecol 29:548-553

Alvarado-Cruz I, Alegria-Torres JA, Montes-Castro N, Jimenez-Garza O, Quintanilla-Vega B (2018) Environmental epigenetic changes, as risk factors for the development of diseases in children: a systematic review. Ann Glob Health 84:212-224

America's Health Rankings (2020) 'Health of Women and Children: Public Health Impact: Obesity - Women', United Health Foundation, America's Health Rankings. https://www.americashealthr ankings.org/explore/health-of-women-and-children/measure/ Obesity_women/state/ALL. Accessed 15 Jul 2020

Ashrap P, Sanchez BN, Tellez-Rojo MM, Basu N, Tamayo-Ortiz M, Peterson KE, Meeker JD, Watkins DJ (2019) In utero and peripubertal metals exposure in relation to reproductive hormones and sexual maturation and progression among girls in Mexico City. Environ Res 177:108630

ATSDR (2011a) 'Environmental Health and Medicine Education. Arsenic Toxicity: What Are the Standards and Regulation for Arsenic Exposure?', U.S. Department of Health and Human Services, Centers for Disease Control and Prevention, Agency for Toxic Substances and Disease Registry. https://www.atsdr.cdc. gov/csem/csem.asp?csem $=1 \& p o=8$. Accessed July 15 Jul 2011

ATSDR (2011b) 'Environmental Health and Medicine Education. Cadmium Toxicity: What Are the Standards and Regulation for Cadmium Exposure?', U.S. Department of Health and Human Services, Centers for Disease Control and Prevention, Agency 
for Toxic Substances and Disease Registry. https://www.atsdr.cdc. gov/csem/csem.asp?csem=6\&po=7. Accessed July $15 \mathrm{Jul} 2011$

ATSDR (2020) 'ATSDR's Substance Priority List Agency for Toxic Substances and Disease Registry', U.S. Department of Health \& Human Services, Center for Disease Control and Prevention, Agency for Toxic Substances and Disease Registry. https://www. atsdr.cdc.gov/SPL/. Accessed July 15 Jul 2011

Barai M, Ahsan N, Paul N, Hossain K, Abdur Rashid M, Kato M, Ohgami N, AzimAkhand A (2017) Amelioration of arsenicinduced toxic effects in mice by dietary supplementation of Syzygiumcumini leaf extract. Nagoya J Med Sci 79:167-177

Bhowmick S, Halder D, Kundu AK, Saha D, Iglesias M, Nriagu J, Mazumder DNG, Roman-Ross G, Chatterjee D (2013) Is Saliva a potential biomarker of arsenic exposure? A case-control study in West Bengal, India. Environ Sci Technol 47:3326

Bondurant KL, Harvey S, Klimberg S, Kadlubar S, Phillips MM (2011) Establishment of a southern breast cancer cohort. Breast J 17:281-288

Bulka CM, Mabila SL, Lash JP, Turyk ME, Argos M (2017) Arsenic and obesity: a comparison of urine dilution adjustment methods. Environ Health Perspect 125:087020

CASRN E. S. C. E. S. (2014) Method 6020B: Inductively Coupled Plasma-Mass Spectrometry. In: U.S. Environmental Protection Agency (ed) Research Triangle Park, NC

CDC (2019) Adult Obesity Prevalence Maps, U.S. Department of Health \& Human Services, Center for Disease Control and Prevention, Division of Nutrition, Physical Activity, and Obesity, National Center for Chronic Disease Prevention and Health Promotion. https://www.cdc.gov/obesity/data/prevalence-maps.html. Accessed July 15 Jul 2019

Ceja-Galicia ZA, Daniel A, Salazar AM, Panico P, Ostrosky-Wegman P, Diaz-Villasenor A (2017) Effects of arsenic on adipocyte metabolism: is arsenic an obesogen? Mol Cell Endocrinol 452:25-32

Chatterjee A, Chatterji U (2010) Arsenic abrogates the estrogen-signaling pathway in the rat uterus. ReprodBiolEndocrinol 8:80

Chen YW, Yang CY, Huang CF, Hung DZ, Leung YM, Liu SH (2009) Heavy metals, islet function and diabetes development. Islets 1:169-176

Church TS, Thomas DM, Tudor-Locke C, Katzmarzyk PT, Earnest CP, Rodarte RQ, Martin CK, Blair SN, Bouchard C (2011) Trends over 5 decades in U.S. occupation-related physical activity and their associations with obesity. PLoS ONE 6:e19657

Davey JC, Bodwell JE, Gosse JA, Hamilton JW (2007) Arsenic as an endocrine disruptor: effects of arsenic on estrogen receptormediated gene expression in vivo and in cell culture. ToxicolSci 98:75-86

Ditzel EJ, Nguyen T, Parker P, Camenisch TD (2016) Effects of arsenite exposure during fetal development on energy metabolism and susceptibility to diet-induced fatty liver disease in male mice. Environ Health Perspect 124:201-209

Farzan SF, Karagas MR, Chen Y (2013) In utero and early life arsenic exposure in relation to long-term health and disease. ToxicolApplPharmacol 272:384-390

Ferrara CM, Lynch NA, Nicklas BJ, Ryan AS, Berman DM (2002) Differences in adipose tissue metabolism between postmenopausal and perimenopausal women. J ClinEndocrinolMetab $87: 4166-4170$

Garaulet M, Perez-Llamas F, Baraza JC, Garcia-Prieto MD, Fardy PS, Tebar FJ, Zamora S (2002) Body fat distribution in pre-and postmenopausal women: metabolic and anthropometric variables. $\mathrm{J}$ Nutr Health Aging 6:123-126

Garhammer P, Hiller KA, Reitinger T, Schmalz G (2004) Metal content of saliva of patients with and without metal restorations. Clin Oral Investig 8:238-242
Gomez-Rubio P, Roberge J, Arendell L, Harris RB, O'Rourke MK, Chen Z, Cantu-Soto E, Meza-Montenegro MM, Billheimer D, Lu Z, Klimecki WT (2011) Association between body mass index and arsenic methylation efficiency in adult women from southwest U.S. and northwest Mexico. ToxicolApplPharmacol 252:176-182

Hodson L, Banerjee R, Rial B, Arlt W, Adiels M, Boren J, Marinou K, Fisher C, Mostad IL, Stratton IM, Barrett PH, Chan DC, Watts GF, Harnden K, Karpe F, Fielding BA (2015) Menopausal status and abdominal obesity are significant determinants of hepatic lipid metabolism in women. J Am Heart Assoc 4:e002258

Hopenhayn C, Bush HM, Bingcang A, Hertz-Picciotto I (2006) Association between arsenic exposure from drinking water and anemia during pregnancy. J Occup Environ Med 48:635-643

IARC (2012a) Arsenic and arsenic compounds. In: World Health Organization (ed) IARC monographs on the evaluation of the carcinogenic risk of chemicals to humans, pp 121-46. World Health Organization, International Agency for Research on Cancer, Lyon, France

IARC (2012b) Cadmium and cadmium compounds. In: World Health Organisation (ed) IARC monographs on the evaluation of carcinogenic risks to humans, pp 121-46. World Health Organization, Internation Agency for Research on Cancer.

Iavicoli I, Fontana L, Bergamaschi A (2009) The effects of metals as endocrine disruptors. J Toxicol Environ Health B Crit Rev $12: 206-223$

Eunice Kennedy Shriver National Institute of Child Health and Human Development (2016) What causes obesity \& overweight? US Department of Health and Human Services, National Institutes of Health, Eunice Kennedy Shriver National Institute of Child Health and Human Development. https:// www.nichd.nih.gov/health/topics/obesity/conditioninfo/cause. Accessed July 15 Jul 2016

Kruger J, Galuska DA, Serdula MK, Jones DA (2004) Attempting to lose weight: specific practices among U.S. adults. Am J Prev Med 26:402-406

Lanza ST, Savage JS, Birch LL (2010) Identification and prediction of latent classes of weight-loss strategies among women. Obesity (Silver Spring) 18:833-840

Lee JY, Klimberg S, Bondurant KL, Phillips MM, Kadlubar SA (2014) Cross-sectional study to assess the association of population density with predicted breast cancer risk. Breast J 20:615-621

Liu R, Nelson DO, Hurley S, Hertz A, Reynolds P (2015) Residential exposure to estrogen disrupting hazardous air pollutants and breast cancer risk: the California Teachers Study. Epidemiology 26:365-373

Lopomo A, Burgio E, Migliore L (2016) Epigenetics of Obesity. ProgMolBiolTranslSci 140:151-184

Lovejoy JC (2003) The menopause and obesity. Prim Care 30:317-325

McElfish PA, Su LJ, Lee JY, Runnells G, Henry-Tillman R, Kadlubar SA (2019) Mobile mammography screening as an opportunity to increase access of rural women to breast cancer research studies. Breast Cancer (Auckl) 13:1178223419876296

Milton AH, Smith W, Rahman B, Hasan Z, Kulsum U, Dear K, Rakibuddin M, Ali A (2005) Chronic arsenic exposure and adverse pregnancy outcomes in Bangladesh. Epidemiology 16:82-86

Milton AH, Hussain S, Akter S, Rahman M, Mouly TA, Mitchell K (2017) A review of the effects of chronic arsenic exposure on adverse pregnancy outcomes. Int J Environ Res Public Health 14:10

Munoz MP, Valdes M, Munoz-Quezada MT, Lucero B, Rubilar P, Pino $\mathrm{P}$, Iglesias V (2018) Urinary inorganic arsenic concentration and gestational diabetes mellitus in pregnant women from Arica, Chile. Int J Environ Res Public Health 15:10

NCHS (2016) Obesity and Overweight, U.S. Department of Health and Human Services, Center for Disease Control and Prevention, 
National Center for Health Statistics. https://www.cdc.gov/nchs/ fastats/obesity-overweight.htm. Accessed 15 Jul 2016

Padilla MA, Elobeid M, Ruden DM, Allison DB (2010) An examination of the association of selected toxic metals with total and central obesity indices: NHANES 99-02. Int J Environ Res Public Health 7:3332-3347

Pappas RS (2011) Toxic elements in tobacco and in cigarette smoke: inflammation and sensitization. Metallomics 3:1181-1198

Park SS, Skaar DA, Jirtle RL, Hoyo C (2017) Epigenetics, obesity and early-life cadmium or lead exposure. Epigenomics 9:57-75

Rahman A, Vahter M, Smith AH, Nermell B, Yunus M, El Arifeen S, Persson LA, Ekstrom EC (2009) Arsenic exposure during pregnancy and size at birth: a prospective cohort study in Bangladesh. Am J Epidemiol 169:304-312

Ronco AM, Gutierrez Y, Gras N, Munoz L, Salazar G, Llanos MN (2010) Lead and arsenic levels in women with different body mass composition. Biol Trace Elem Res 136:269-278

Schmidt CW (2014) Low-dose arsenic: in search of a risk threshold. Environ Health Perspect 122:A130-A134

Smith DB, Solano F, Woodruff FG, Cannon WF, Ellefsen KJ (2017) Geochemical and Mineralogical Maps, with Interpretation, for Soils of the Conterminous United States, U.S. Department of the Interior, U.S. Geological Survey Intranet. https://pubs.usgs.gov/ sir/2017/5118/sir20175118_element.php?el=33. Accessed $15 \mathrm{Jul}$ 2017

Sterling T, Weinkam J (1990) The confounding of occupation and smoking and its consequences. SocSci Med 30:457-467

Surdu S, Bloom MS, Neamtiu IA, Pop C, Anastasiu D, Fitzgerald EF, Gurzau ES (2015) Consumption of arsenic-contaminated drinking water and anemia among pregnant and non-pregnant women in northwestern Romania. Environ Res 140:657-660

Thomas R (2004) Practiccal Guide to ICP-MS. Marcel Dekker INC, New York

Tinkov AA, Filippini T, Ajsuvakova OP, Aaseth J, Gluhcheva YG, Ivanova JM, Bjorklund G, Skalnaya MG, Gatiatulina ER, Popova EV, Nemereshina ON, Vinceti M, Skalny AV (2017) The role of cadmium in obesity and diabetes. Sci Total Environ 601-602:741-755
Waalkes MP, Liu J, Chen H, Xie Y, Achanzar WE, Zhou YS, Cheng ML, Diwan BA (2004) Estrogen signaling in livers of male mice with hepatocellular carcinoma induced by exposure to arsenic in utero. J Natl Cancer Inst 96:466-474

Wang D, Shimoda Y, Wang S, Wang Z, Liu J, Liu X, Jin H, Gao F, Tong J, Yamanaka K, Zhang J, An Y (2017) Total arsenic and speciation analysis of saliva and urine samples from individuals living in a chronic arsenicosis area in China. Environ Health Prev Med 22:45

Wang Y, Beydoun MA, Min J, Xue H, Kaminsky LA, Cheskin LJ (2020) Has the prevalence of overweight, obesity and central obesity levelled off in the United States? Trends, patterns, disparities, and future projections for the obesity epidemic. Int J Epidemiol. 49:810-823

White AJ, Weinberg CR, O'Meara ES, Sandler DP, Sprague BL (2019) Airborne metals and polycyclic aromatic hydrocarbons in relation to mammographic breast density. Breast Cancer Res 21:24

Wilschefski SC, Baxter MR (2019) Inductively coupled plasma mass spectrometry: introduction to analytical aspects. ClinBiochem Rev 40:115-133

Xue P, Hou Y, Zhang Q, Woods CG, Yarborough K, Liu H, Sun G, Andersen ME, Pi J (2011) Prolonged inorganic arsenite exposure suppresses insulin-stimulated AKT S473 phosphorylation and glucose uptake in 3T3-L1 adipocytes: involvement of the adaptive antioxidant response. BiochemBiophys Res Commun 407:360-365

Yuan C, Lu X, Oro N, Wang Z, Xia Y, Wade TJ, Mumford J, Le XC (2008) Arsenic speciation analysis in human saliva. ClinChem $54: 163-171$

Zhou Z, Lu YH, Pi HF, Gao P, Li M, Zhang L, Pei LP, Mei X, Liu L, Zhao Q, Qin QZ, Chen Y, Jiang YM, Zhang ZH, Yu ZP (2016) Cadmium exposure is associated with the prevalence of dyslipidemia. Cell PhysiolBiochem 40:633-643

Publisher's Note Springer Nature remains neutral with regard to jurisdictional claims in published maps and institutional affiliations. 